\title{
'Unscrambling' the drivers of egg production in Agassiz's desert tortoise: climate and individual attributes predict reproductive output
}

\author{
Corey I. Mitchell ${ }^{1,7, *}$, Derek A. Friend ${ }^{1, \#}{ }^{,}$Lauren T. Phillips ${ }^{1, \#}{ }^{,}$, Elizabeth A. Hunter ${ }^{2}$, \\ Jeffrey E. Lovich ${ }^{3}$, Mickey Agha ${ }^{4}$, Shellie R. Puffer ${ }^{3}$, Kristy L. Cummings ${ }^{3}$, Philip A. \\ Medica $^{5, \mathrm{~F}}$, Todd C. Esque ${ }^{5}$, Kenneth E. Nussear ${ }^{1}$, Kevin T. Shoemaker ${ }^{6}$ \\ ${ }^{1}$ Department of Geography, University of Nevada, Reno, NV 89557, USA \\ ${ }^{2}$ Department of Biology, Georgia Southern University, Statesboro, GA 30460, USA \\ ${ }^{3}$ US Geological Survey Southwest Biological Science Center, Flagstaff, AZ 86001, USA \\ ${ }^{4}$ Washington Department of Fish and Wildlife, Olympia, WA 98501, USA \\ ${ }^{5}$ US Geological Survey Western Ecological Research Center, Henderson, NV 89074, USA \\ ${ }^{6}$ Department of Natural Resources and Environmental Science, University of Nevada, Reno, NV 89557, USA \\ ${ }^{7}$ Present address: Desert Centered Ecology, LLC, Tucson, AZ 85716, USA
}

\begin{abstract}
The 'bet hedging' life history strategy of long-lived iteroparous species reduces short-term reproductive output to minimize the risk of reproductive failure over a lifetime. For desert-dwelling ectotherms living in variable and unpredictable environments, reproductive output is further influenced by precipitation and temperature via effects on food availability and limits on activity. We assembled multiple $(n=12)$ data sets on egg production for the threatened Agassiz's desert tortoise Gopherus agassizii across its range and used these data to build a rangewide predictive model of annual reproductive output as a function of annual weather variation and individual-level attributes (body size and prior-year reproductive status). Climate variables were more robust predictors of reproductive output than individual-level attributes, with overall reproductive output positively related to prior-year precipitation and an earlier start to the spring activity season, and negatively related to spring temperature extremes (monthly temperature range in March-April). Reproductive output was highest for individuals with larger body sizes that reproduced in the previous year. Expected annual reproductive output from 1990-2018 varied from 2-5 to 6-12 eggs female ${ }^{-1} \mathrm{yr}^{-1}$, with a weak decline in expected reproductive output over this time $(p=0.02)$. Climate-driven environmental variation in expected reproductive output was highly correlated across all 5 Recovery Units for this species (Pearson's r > 0.9). Overall, our model suggests that climate change could strongly impact the reproductive output of Agassiz's desert tortoise, and could have a negative population-level effect if precipitation is significantly reduced across the species' range as predicted under some climate models.
\end{abstract}

KEY WORDS: Gopherus agassizii $\cdot$ Climate change $\cdot$ Fecundity $\cdot$ Population ecology $\cdot$ Meta-analysis

\section{INTRODUCTION}

Variation in reproductive output is an important determinant of population dynamics, and understanding the drivers of this variation is necessary for

\footnotetext{
*Corresponding author: coreyirene@gmail.com

\#These authors contributed equally

${ }^{\text {T} D e c e a s e d ~} 3$ May 2020
}

predicting future population trends, performing scenario tests (e.g. threat assessment and ranking management actions), and preparing population viability analyses (PVA; e.g. Reed et al. 2009). Reproductive success is influenced by many factors, including the USA, the US Government 2021. Open Access under Creative Commons by Attribution Licence. Use, distribution and reproduction are unrestricted. Authors and original publication must be credited. Publisher: Inter-Research - www.int-res.com 
habitat quality (Powell \& Steidl 2000, Blanchfield \& Ridgway 2005) and levels of disturbance (Anthonysamy et al. 2014), external pressures such as predation and available forage (Bjurlin \& Bissonette 2004, Zanette et al. 2006), individual physiological condition (Henen 2002, Vleck \& Vleck 2002), and genetic differences between populations (Hagerty \& Tracy 2010), among others. Many of these factors are driven or influenced by annual weather and changes in climate, which therefore can play a major role in reproductive success. For desert-dwelling animals, water availability can be a critical determinant of reproductive success, both directly via hydration and indirectly via the effects of precipitation on primary production (Beatley 1974, Smith et al. 1995, Wallis et al. 1999). Temperature can also be a critically important driver of reproductive success, especially for ectothermic species, whose bioenergetic processes and activity patterns can be extremely sensitive to alterations in the thermal environment (Clarke \& Zani 2012, Zeh et al. 2012).

The impact of short-term climate-driven variation in reproductive output on population growth and extinction risk varies across life history types. With their 'bet hedging' life history strategy, long-lived iteroparous species are generally considered to be less vulnerable to short-term disruptions to reproduction than are semelparous species (Stearns 1976, Lovich et al. 2015). Nonetheless, long-lived species must maintain mean reproductive output above a critical minimum threshold for viability, and longterm changes in climate at generational time scales could push reproductive rates below sustainable levels (van de Pol et al. 2010). Furthermore, populations of long-lived species can persist for many years after reproductive rates fall below sustainable levels (Lovich et al. 2018a), often creating a misleading perception of population sustainability. Therefore, it is critical to understand and predict the long-term effects of climate variation on reproductive success for such species.

The threatened Agassiz's desert tortoise Gopherus agassizii (USFWS 1990) is a long-lived desertdwelling ectotherm whose physiology and behavior are strongly influenced by environmental conditions such as precipitation and temperature (Nagy \& Medica 1986, Zimmerman et al. 1994, Lovich et al. 2012). As is many other reptiles, reproduction in the desert tortoise is seasonal, and larger females tend to produce more eggs than females with smaller body size (Turner et al. 1986, Mueller et al. 1998). However, body size typically only explains a small proportion of variation in reproductive output, and thus other exogenous factors also drive reproduction for this species (Wallis et al. 1999). Temperature appears to be a proximate cue for physiological changes and behavior related to the reproductive cycle as well as a determining factor for the length of the nesting season (Rostal et al. 1994, Lovich et al. 2012). Additionally, as an obligate herbivore, many aspects of desert tortoise ecology tied to fecundity, growth, and survivorship are positively correlated with the diversity and annual biomass of vegetation communities (Longshore et al. 2003, Medica et al. 2012). These processes are highly dependent on precipitation, which is extremely variable in the desert ecosystems occupied by the desert tortoise (Noy-Meir 1973, Beatley 1974). In fact, several analyses of desert tortoise egg production at long-term study sites have detected effects of temperature and precipitation on total annual reproductive output (Wallis et al. 1999, Henen 2002, Nussear et al. 2012, Lovich et al. 2012). While these studies provide important insight into the effects of climate on annual variation in reproduction, detecting long-term trends in reproductive output is also a crucial component of conservation efforts. Recovery efforts for this species are focused on increasing tortoise abundance (USFWS 2011); therefore, an understanding of the factors that influence desert tortoise fecundity, on an annual scale as well as longterm trends, is fundamental to informing these efforts. Furthermore, with climate regimes across the species' range expected to exhibit rapid shifts in coming decades (Seager et al. 2007, Barrows 2011), understanding the range-wide climatic drivers of reproductive success in this species is critical for assessing its future conservation outlook.

The objective of this study was to understand the endogenous (e.g. body size) and exogenous (e.g. climate) drivers of reproductive output (total number of eggs female ${ }^{-1} \mathrm{yr}^{-1}$ ) for Agassiz's desert tortoise, and to build a predictive model of egg production as a function of environmental conditions across the range of this species. Our study included multiple years of sampling at study sites across a large extent of the species' range. We summarized our data at the level of the US Fish and Wildlife designated Recovery Unit (RU) for the tortoise, as this not only reflects a tangible metric for management of the species, but the RUs are delineated based on estimations of genetic structure of desert tortoise populations (Hagerty \& Tracy 2010, USFWS 2011). Based on a priori knowledge of this species (see Section 2.1) and other turtle and tortoise species (Ernst \& Lovich 2009), we hypothesized that increased female body size (midline carapace length, MCL) would have a 
positive effect on reproductive output. We also hypothesized that higher total precipitation in the year leading up to the start of the nesting season would improve forage quality and availability during both vitellogenesis and egg production processes and thereby have a positive effect on reproductive output. Finally, we predicted that years with an earlier start to the activity season (driven by high spring temperatures early in the activity season) would be conducive to higher reproductive output, primarily due to enabling more females to produce multiple clutches (Wallis et al. 1999).

\section{MATERIALS AND METHODS}

\subsection{Desert tortoise reproductive cycle}

The reproductive cycle of the female Agassiz's desert tortoise starts in late summer/early fall with follicular enlargement during vitellogenesis (coinciding with peak air temperatures; Rostal et al. 1994) (Fig. 1). This is followed by a fall mating period before activity decreases and tortoises seek winter hibernacula (Nussear et al. 2007). Upon emergence from hibernacula in the spring, when air temperatures increase to within the typical range of activity for this species (February-April; Nussear et al. 2007), ovulation and spring mating occur followed by oviductal shelling and tortoise nesting (Rostal et al. 1994). Females typically produce 1-3 clutches over the course of the nesting season, which generally occurs from May-July (although late April lay dates have been observed; Turner et al. 1986, 1984); females occasionally forgo reproduction. Following the end of the nesting period in mid- to late summer, there is a brief latent period before follicular enlargement begins and the cycle repeats.

\subsection{Egg production data}

Desert tortoise annual egg production data were acquired from 12 study sites distributed across the range of the species (Fig. 2). Data were collected from 1997-2018 as part of 7 separate studies (Table 1; some studies included $>1$ site), although data were not collected at all sites in each year (see Text S1 in the Supplement at www.int-res.com/articles/suppl/ n044p217_supp.pdf for site-specific information). Study sites were located within 4 of the 5 revised RUs for the desert tortoise: Upper Virgin River, Northeastern Mojave, Eastern Mojave, and Colorado Desert (USFWS 2011). Reproductive data in the Western Mojave RU were not available for this study, and applicability of resulting predictions may be limited in that region due to climatic differences between the Western Mojave and the rest of the range. Because the range of Agassiz's desert tortoise extends over most of the Mojave Desert and the western portion of the Sonoran Desert, it encompasses broad climatic and elevational gradients (Nussear \& Esque 2019).

In all studies used in our analyses, radio-transmitters were attached to the carapace of females and VHF radio-telemetry was used to relocate animals to assess reproductive status. Egg production was

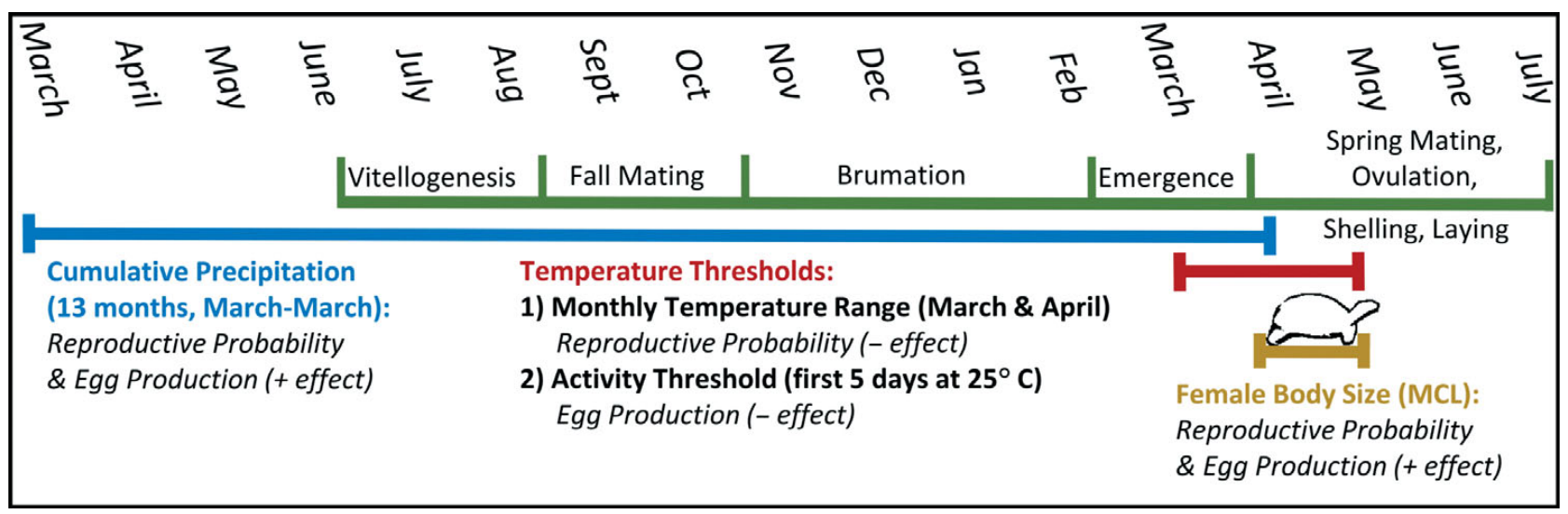

Fig. 1. Generalized reproductive cycle for Agassiz's desert tortoise Gopherus agassizii in relation to climate and individuallevel covariates. The 'windows' for summarizing climate variables were determined based on a priori reasoning (activitytemperature threshold) or were empirically derived ('climwin' package for $\mathrm{R}_{i}$ cumulative precipitation, monthly temperature range). Covariates designated with ' + ' and ' - ' denote positive and negative effects on the reproductive probability and total egg production processes, based on a fitted hierarchical Bayesian model of annual reproductive output. MCL: midline carapace length 


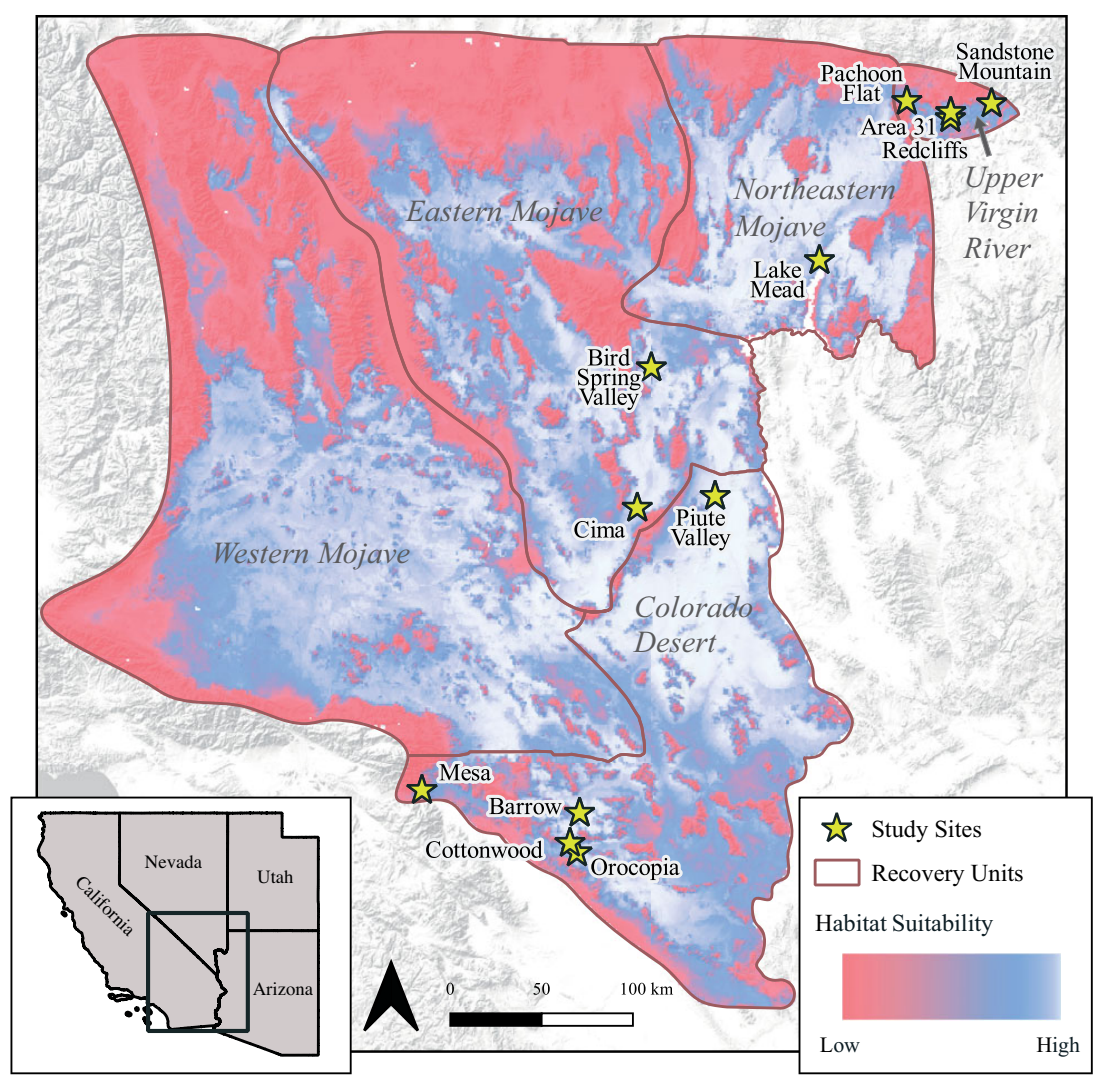

Fig. 2. Study sites $(\mathrm{n}=12)$ and 2011 US Fish and Wildlife Service Revised Recovery Units (USFWS 2011) superimposed over the habitat suitability model for Agassiz's desert tortoise Gopherus agassizii used in Edwards et al. (2015)

determined from X-radiographs taken at mostly weekly or biweekly intervals (depending on the study) using a portable X-ray machine between April and July or August of each year (Fig. S1). In addition, tortoises were weighed with spring scales $(g)$ and their MCLs were measured using calipers (mm). Because multiple data sets based on differing protocols were collated for this analysis, we lacked necessary measurements on each individual for estimating a body score index (i.e. mass/volume; Wallis et al. 1999) and data collection precluded the adoption of visual body condition scoring into the standard sampling protocol (Lamberski 2013). A nesting event was recorded if a female previously observed with eggs was observed without eggs during a subsequent $\mathrm{X}$ ray session. For a more detailed description of field methods see Lovich et al. (2015) and Nussear et al. (2012).

\subsection{Climate data}

Monthly climate data, that is mean daily maximum temperature $\left(T_{\max }\right)$, mean daily minimum temperature $\left(T_{\min }\right)$, and total precipitation $(\mathrm{mm})$, were obtained from the PRISM database (PRISM Climate Group 2019; $800 \mathrm{~m}$ resolution). The monthly temperature range (MTR) was derived by subtracting $T_{\min }$ from $T_{\max }$. Daily temperatures were obtained from Daymet (Thornton et al. 2018; $1 \mathrm{~km}^{2}$ resolution). We used Daymet data to determine the initiation of the spring activity period (activity-temperature threshold), which we defined as the first calendar day on which the maximum daily

Table 1. Summary and sources for data on reproductive output of Agassiz's desert tortoise Gopherus agassizii

\begin{tabular}{|c|c|c|c|c|c|}
\hline Site & Survey period & No. of years & Individual tortoises & Total observations & Source \\
\hline Area 31 & $1998-2000$ & 3 & 14 & 34 & Nussear et al. (2012) \\
\hline Barrow & 1997-1999 & 3 & 7 & 12 & Lovich et al. (1999) \\
\hline Bird Spring Valley & $1997-2002$ & 6 & 71 & 216 & $\begin{array}{l}\text { Nussear et al. (2012), } \\
\text { P. A. Medica unpubl. data }\end{array}$ \\
\hline Cima & $1997-2000$ & 4 & 28 & 69 & $\begin{array}{c}\text { Lovich et al. (1999), } \\
\text { P. A. Medica unpubl. data }\end{array}$ \\
\hline Cottonwood & $2015-2016$ & 2 & 7 & 10 & Lovich et al. (2018b) \\
\hline Lake Mead & 1998-1999 & 2 & 20 & 35 & Nussear et al. (2012) \\
\hline Mesa & $1997-2000$ & 4 & 18 & Lov & ovich et al. $(1999,2012,2015)$ \\
\hline Orocopia & $2017-2018$ & 2 & 4 & 7 & Lovich et al. (2019) \\
\hline Pahcoon Flat & 1998-2000 & 3 & 6 & 13 & Nussear et al. (2012) \\
\hline Piute Valley & 1998-2002 & 5 & 37 & 75 & P. A. Medica unpubl. data \\
\hline Redcliffs & 1998 & 1 & 10 & 10 & T. C. Esque unpubl. data \\
\hline Sandstone Mountain & 1999-2000 & 2 & 4 & 6 & Nussear et al. (2012) \\
\hline Summary & $1997-2018$ & 37 & 226 & 536 & \\
\hline
\end{tabular}


temperature reached or exceeded $25^{\circ} \mathrm{C}$ for 5 consecutive days (based on Zimmerman et al. 1994, which indicated minimal tortoise activity below $25^{\circ} \mathrm{C}$ ). Inclusion of the activity-temperature threshold variable was based on findings by Wallis et al. (1999) that the earlier in the season a female developed a clutch of eggs, the greater the total annual reproductive output due to the potential for development of multiple clutches. The climate variables used for further analysis were not highly correlated during the study period (Pearson's $|r|<0.7$ ).

\subsection{Identifying appropriate climate 'windows'}

We used moving window analyses to determine optimal time windows for modeling egg production ('climate windows'; implemented in the 'climwin' package for R; Bailey \& van de Pol 2016, van de Pol et al. 2016). For each climate variable ( $T_{\max }, \mathrm{MTR}$, and precipitation) and for each reproductive process (reproductive probability [RP], egg production [EP]; see below), we assessed all possible climate windows in the 18 mo period leading up to the 1 May initiation of the nesting period in 1 mo increments (570 models: 3 climate variables $\times 190$ climate windows). Variables were aggregated as the mean (for temperature variables) or sum (for precipitation) of all values within the climate window. We chose an 18 mo maximum time lag because current-year fecundity may plausibly be affected by current as well as previousyear vegetation availability (via capital energy reserves; Henen 2004), which could be driven by precipitation from the previous winter. We did not conduct a climate window analysis for the activitytemperature threshold variable, which was based on a well-specified a priori hypothesis (see Section 2.3).

We used logistic regression to model RP and Poisson regression to model EP (using total annual egg counts for all females that produced $\geq 1$ clutch). The 'baseline' models for both reproductive processes (upon which climate variables were subsequently added) included female body size (MCL). We compared all models to the baseline (MCL-only) model using Akaike's information criterion corrected for small sample size (AICc). To guard against inflated Type I error due to multiple comparisons, we used a permutation test (100 randomizations) implemented in 'climwin' that iteratively re-ran the climate window analysis with randomized dates (Bailey \& van de Pol 2016, van de Pol et al. 2016). The top model ('optimal' climate window) was then compared to the null distribution of $\triangle \mathrm{AICC}$ scores to calculate the likeli- hood that its $\triangle \mathrm{AICC}$ score occurred by chance (PAAICc). We only interpreted climate covariates with $\mathrm{P} \triangle \mathrm{AICC}<0.05$.

\subsection{Predictive model of desert tortoise reproductive success}

We fitted our final egg production model using a Bayesian hierarchical modeling framework, which enables researchers to fit complex models that integrate multiple ecological processes and sources of error (Clark 2005). The hierarchical model we constructed consisted of an RP process model and an EP process model. In this framework, individuals either reproduce or not each year (with probability determined on the basis of the RP model), and the total number of eggs produced each year by each reproductive tortoise is determined on the basis of the EP model. We modeled RP as a Bernoulli process and EP as a Poisson process, analogous to a 'zero inflated Poisson' model (Zuur et al. 2009). We rescaled all continuous covariates (MCL, climate variables; see Table 2) to have a mean of 0 and standard deviation of 1.

The expected probability of reproducing for each individual each year was modeled as a logit-linear function of the observed reproductive status of individuals in the year prior, MCL, cumulative prior-year precipitation, and mean MTR from March-April of the current year. Mean egg production for each tortoise in each year (conditional upon being reproductive) was modeled as a log-linear function of MCL, cumulative precipitation, and the activity-temperature threshold. Specifically, we modeled the RP and EP processes using the following equations:

RP process:

$$
\begin{aligned}
\operatorname{logit}\left(p R_{i j}\right)= & \operatorname{logit}(b p R)+\beta_{1} r s_{i j-1}+ \\
& \beta_{2} c p_{i j}+\beta_{3} m c l_{i j}+\beta_{4} m t r_{i j}
\end{aligned}
$$

EP process:

$$
\begin{aligned}
\log \left(E E_{i j}\right)= & \log (B E)+\beta_{5} C p_{i j}+ \\
& \beta_{6} m c l_{i j}+\beta_{7} a t t_{i j}
\end{aligned}
$$

where $p R_{i j}$ is the probability of individual $i$ reproducing in year $j, b p R$ is the baseline probability of reproducing (logit scale), $r s_{i j-1}$ is the observed or estimated (latent) reproductive status of individual $i$ in year $j-1$, $c p_{i j}$ is cumulative prior-year precipitation for individual $i$ in year $j, m_{c} l_{i j}$ is the MCL for individual $i$ in year $j, m t r_{i j}$ is the mean MTR for individual $i$ in year $j, E E_{i j}$ is the expected number of eggs produced by individual $i$ in year $j, B E$ is the baseline number of eggs pro- 
duced annually by reproductive females (log scale), $a t t_{i j}$ is the activity-temperature threshold date (see Table 2), and $\beta_{1-7}$ represent regression coefficients. For Bayesian parameter estimation, $b p R$ was assigned a vague $\operatorname{Beta}(1,1)$ prior and $B E$ was assigned a Uniform $(1,15)$ prior. All other regression coefficients were assigned Gaussian priors with a mean of 0 and variance of 10 .

Models were fitted in R v.3.6.0 using a Markov Chain Monte Carlo algorithm implemented in the JAGS software (Plummer 2017, R Core Team 2019), which was called from $\mathrm{R}$ using the 'runjags' package (Denwood 2016). We ran 3 independent chains for 25000 iterations each after a burn-in sample of 2000, and stored every $10^{\text {th }}$ run for a total of 7500 joint posterior samples. Model convergence for each parameter was inspected by visually examining traceplots and by examining the Gelman-Rubin and the Heidelberger and Welch convergence diagnostic tests (Heidelberger \& Welch 1983, Brooks \& Gelman 1998). All code and data for fitting this model are available at https:// github.com/kevintshoemaker/TortoiseEggModel.

\subsection{Model validation}

To assess goodness-of-fit, we simulated multiple additional data sets based on parameter values drawn from the fitted joint posterior distribution. In order to quantify whether the observed data could plausibly have been generated from our best fit model, we computed the root mean squared error (RMSE) for the simulated data sets and contrasted these values with RMSEs computed for the observed data. We calculated a Bayesian posterior predictive p-value (metric of goodness-of-fit) as the fraction of instances in which the RMSE values from simulated data sets exceeded the RMSE values computed using the observed data set (Kéry 2010). In general, a p-value close to 0.5 generated under these methods demonstrates that the model's predictions are close to the observed data (Kéry 2010, Gelman et al. 2013).

To assess model predictive performance, we ran a 10 fold cross-validation procedure in which one-tenth of individual tortoises were held out from the model fitting process in turn and the observed number of eggs was compared with the predicted number of eggs for all held-out observations. We used area under the curve (AUC; for the RP process) and $\mathrm{R}^{2}$ (for the EP process) metrics to summarize model predictive performance across all holdout samples. Predictive performance for the EP process was only evaluated for observations with $\geq 1$ egg produced. To evaluate the relative contributions of climate variables and individual-level variables to predictive performance, we repeated the cross-validation procedure for (1) a reduced model with only individual-level covariates and (2) a reduced model with only climate covariates.

\subsection{Model interpretation and predictions}

We interpreted covariate effects using 3 sets of partial dependence plots: one depicting the probability of reproducing across the full range of all model covariates, one depicting the total egg production, conditional on reproducing, and the final set depicting the total expected number of eggs (accounting for both reproductive processes).

\subsection{Predictive maps}

Predictive maps of annual egg production potential were calculated using an $800 \times 800 \mathrm{~m}$ grid matching the PRISM data grid over the range of desert tortoise habitat (Carter et al. 2020) using parameters from the best model and raster products of all input data spanning the study area. The mean tortoise MCL used for predictions was calculated from 4579 females using the average from this study, as well as several study sites across the range (Table S1). Annual maps were created for the time period from 1990-2018. To account for the prior year reproduction effect on the reproductive process, we conducted a 10 yr 'burn in', where we set all reproduction values for the initial year to a probability of 1, and cycled the reproductive process (according to the model parameters) over $10 \mathrm{yr}$ prior to calculating the first reproductive process used in map production. The annual egg production for each successive year was then taken as the reproductive process of the prior and current year, along with the egg laying process calculated for the current year. Averaged egg potential values within the 5 RUs (Fig. 2; USFWS 2011) were aggregated to create RUbased estimates of average annual egg production potential. Finally, we computed the Pearson correlation in climate-driven annual variation between each pair of RUs.

\section{RESULTS}

Across all studies, we obtained data on reproductive output for a total of 226 unique females and 536 unique individual-year combinations (Fig. S2). 


\subsection{Climate variable selection and 'climate window' analyses}

Both cumulative precipitation and MTR had meaningful effects on the RP and EP processes, while $T_{\max }$ had no meaningful effect on either. However, the coefficient on MTR in the EP model was not significant and was therefore excluded from our final Bayesian predictive model in favor of the Daymet activitytemperature threshold variable. The optimal climate windows which were incorporated into our final model were cumulative precipitation from 14-2 mo before 1 May (13 mo; March-March) of the nesting year and monthly temperature range from 2-1 mo before 1 May (March-April) of the nesting year (Table 2, Fig. 1).

\subsection{Predictive model of desert tortoise reproductive success}

The fitted Bayesian hierarchical model confirmed the importance of all factors included in the linear model, as none of the $95 \%$ credible intervals for regression coefficients overlapped zero (Table 3). The coefficient estimates indicated positive effects for cumulative precipitation and MCL on both the RP and EP processes, a negative effect of MTR on the RP process, and a negative effect of the calendar day of first activity (activity-temperature threshold) on the
EP process. Variables were standardized prior to the analysis (see Section 2.5); therefore, relative contributions of each variable are interpreted based on the magnitude of the resulting coefficient value. The intercept of the RP model was estimated at $66 \%$ and interpreted as the baseline probability of reproducing for an average female in an average year. Cumulative precipitation had the highest magnitude coefficient value in the RP process $(\beta=0.62)$, resulting in the expected probability of reproducing increasing from $0.76-0.99$ as cumulative precipitation increased from 30.2-637.1 mm (Fig. 3). March-April MTR ( $\beta=$ -0.41 ) also had a significant effect on the RP process, resulting in expected probability of reproduction decreasing from $0.89-0.66$ as temperature range increased from $9.6-19.2^{\circ} \mathrm{C}$. Finally, 2 individual-level attributes - MCL ( $\beta=0.34$ ) and prior-year reproductive status $(\beta=1.46)$ - affected the RP process, with probability of reproduction increasing from $0.76-$ 0.96 over the observed range of MCL (180-289 mm) and increasing from $0.66-0.89$ for females that reproduced in the previous year (Fig. 3). For the EP process, the baseline number of eggs was estimated as 6.5 eggs per average female in an average year. Cumulative precipitation ( $\beta=0.15$ ) had the strongest influence on the EP process, with mean number of eggs expected to increase from 5-13 eggs with an increase from $30.2-637.1 \mathrm{~mm}$ precipitation. The second most influential covariate on the EP process was MCL ( $\beta=0.12)$, with mean number of eggs expected

Table 2. Climate and individual-level covariates used to model reproductive probability (RP) and egg production (EP) for Agassiz's desert tortoise Gopherus agassizii. Abbreviations in parentheses correspond to Eqs. 1 \& 2 in Section 2.5

\begin{tabular}{|c|c|c|}
\hline Covariate & Description & Source \\
\hline \multicolumn{3}{|l|}{ RP process } \\
\hline Reproductive status ( $r s_{i j-1_{i}}$ latent variable) & $\begin{array}{l}\text { Yes/No nesting observed in year prior; recorded } \\
\text { annually for each tortoise }{ }^{\mathrm{a}}\end{array}$ & See Table 1 \\
\hline Cumulative precipitation $\left(c p_{i j}\right)$ & $\begin{array}{l}\text { Cumulative precipitation over the } 13 \text { mo (March- } \\
\text { March) prior to the nesting season }\end{array}$ & $\begin{array}{l}\text { PRISM Climate Group } \\
(2019) ; 800 \mathrm{~m}\end{array}$ \\
\hline Midline carapace length $\left(m c l_{i j}\right)$ & $\begin{array}{l}\text { The length of the carapace measured annually } \\
\text { by caliper for each tortoise (mm) }\end{array}$ & See Table 1 \\
\hline Monthly temperature range $\left(m t_{i j}\right)$ & $\begin{array}{l}\text { The average monthly temperature range (mean } \\
\text { daily maximum - mean daily minimum) of the } \\
2 \text { mo leading to the nesting season (March-April) }\end{array}$ & $\begin{array}{l}\text { PRISM Climate Group } \\
(2019) ; 800 \mathrm{~m}\end{array}$ \\
\hline \multicolumn{3}{|l|}{ EP process } \\
\hline Cumulative precipitation $\left(c p_{i j}\right)$ & $\begin{array}{l}\text { Cumulative precipitation over the } 13 \text { mo (March- } \\
\text { March) prior to the nesting season }\end{array}$ & $\begin{array}{l}\text { PRISM Climate Group } \\
(2019) ; 800 \mathrm{~m}\end{array}$ \\
\hline Midline carapace length $\left(m c l_{i j}\right)$ & $\begin{array}{l}\text { The length of the carapace measured annually } \\
\text { by caliper for each tortoise (mm) }\end{array}$ & See Table 1 \\
\hline Activity-temperature threshold $\left(a t t_{i j}\right)$ & $\begin{array}{l}\text { Calendar day of first } 5 \mathrm{~d} \text { period where the } \\
\text { maximum temperature is above } 25^{\circ} \mathrm{C}\end{array}$ & $\begin{array}{l}\text { Daymet: Thornton } \\
\text { et al. }(2018) ; 1 \mathrm{~km}\end{array}$ \\
\hline
\end{tabular}


Table 3. Parameter estimates for the reproductive probability (RP) and egg production (EP) processes, with corresponding Bayesian credible intervals (95\% highest posterior density)

\begin{tabular}{|lrrr|}
\hline Parameters & Mean & Lower CI & Upper CI \\
\hline RP process & & & \\
bpR: Baseline probability of reproducing & 0.66 & 0.56 & 0.77 \\
$\beta_{1}$ : Reproductive status (year prior) & 1.46 & 0.67 & 2.24 \\
$\beta_{2}$ : Cumulative precipitation & 0.62 & 0.24 & 1.05 \\
$\beta_{3}$ : Midline carapace length & 0.34 & 0.07 & 0.64 \\
$\beta_{4}$ : Monthly temperature range & -0.41 & -0.80 & -0.02 \\
EP process & & & \\
BE: Baseline number of eggs & 6.50 & 6.24 & 6.74 \\
$\beta_{5}$ : Cumulative precipitation & 0.15 & 0.11 & 0.19 \\
$\beta_{6}$ : Midline carapace length & 0.12 & 0.08 & 0.15 \\
$\beta_{7}$ : Activity-temperature threshold & -0.07 & -0.12 & -0.03 \\
\hline
\end{tabular}

to increase from 4.6-9.2 eggs with an MCL increase from 180-289 $\mathrm{mm}$. The activity-temperature threshold ( $\beta=-0.07$ ) had a weak negative effect on the EP process, with egg production expected to decrease from 8-5 eggs as the date of reaching the activity- temperature threshold shifts from late January to mid-June (Fig. 3).

\subsection{Model convergence and performance evaluation}

The potential scale reduction factor and Heidelberger and Welch diagnostics confirmed that all chains converged on the posterior distribution (Gelman et al. 2013). The posterior predictive check resulted in a relatively even division of RMSE values above and below the 1:1 line (Bayesian posterior predictive $p=0.7$ ), suggesting that the model could plausibly have generated the observed data (Gelman 2013). From 10-fold crossvalidation (leaving out entire individuals and thereby eliminating any information about prior reproductive status), we showed that model performance was generally weak for predicting reproductive status
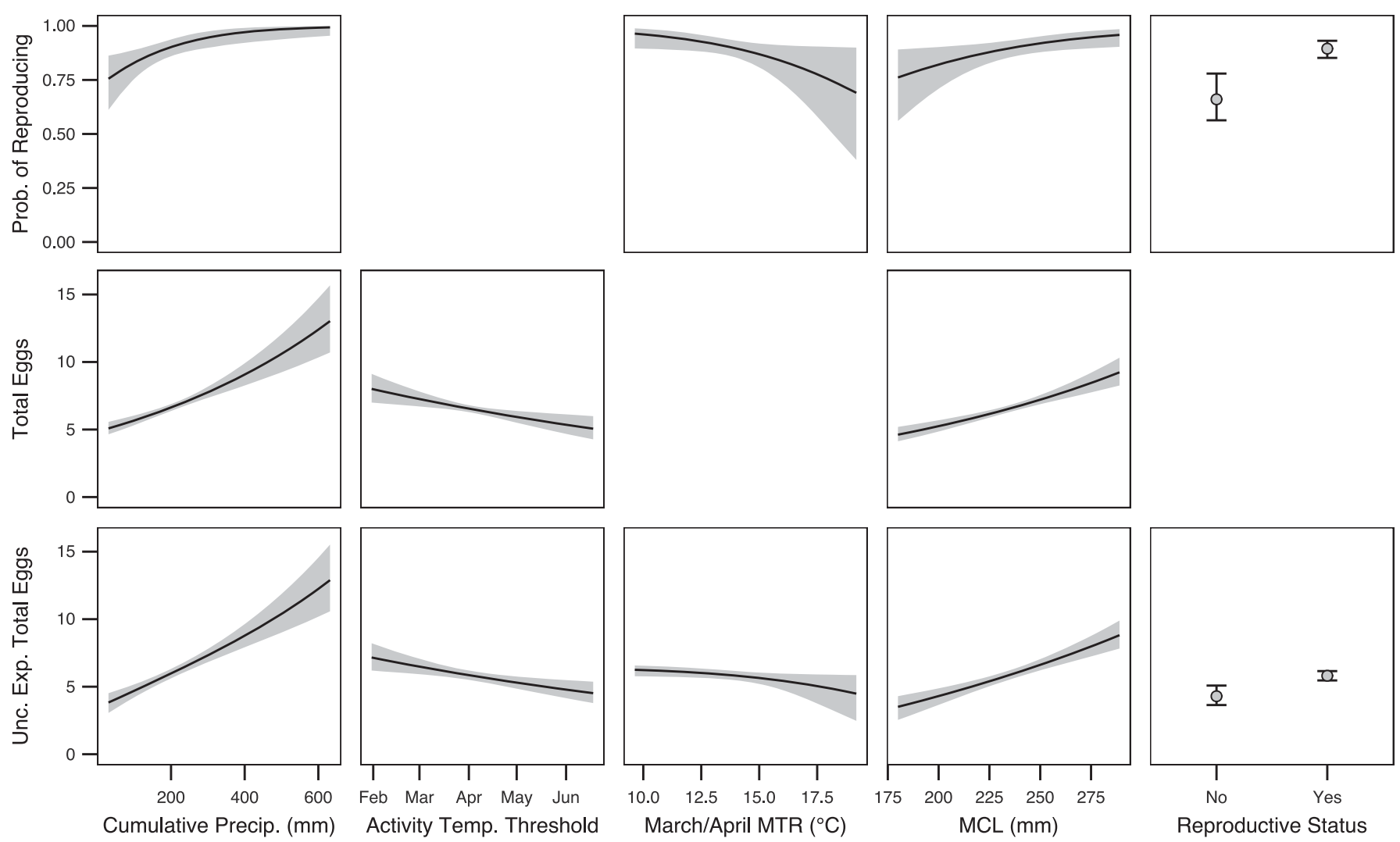

Fig. 3. Partial dependence plots illustrating fitted relationships between reproductive output of Agassiz's desert tortoise Gopherus agassizii and covariates representing climate and individual-level attributes. Top row: expected probability of reproducing; middle row: total egg production conditional on reproducing; bottom row: expected unconditional egg production (accounting for both of the above processes). Predicted means (solid lines or circles) and 95\% credible intervals (gray regions or error bars) were derived from a fitted Bayesian model of annual egg production. MTR: monthly temperature range; MCL: midline carapace length 
$(\mathrm{AUC}=0.67 ; 95 \%$ CI: $0.65-0.7)$. When trained to the full data set, AUC increased to 0.75 (95\% CI: 0.720.79 ). For reproductive individuals, our model explained $30 \%$ of the observed variance in egg production for withheld individuals $\left(\mathrm{R}^{2} ; 95 \%\right.$ CI: 0.28-0.31). When climate variables (precipitation, MTR, activitytemperature threshold) were excluded from the predictive model, AUC for the RP process decreased from 0.67-0.54 (little better than random), and median $\mathrm{R}^{2}$ for the EP process decreased from $0.30-0.23$ in cross-validation. When individual-level covariates (MCL, prior-year reproduction) were excluded from the model, AUC for the RP process increased from 0.67-0.69 and median $\mathrm{R}^{2}$ for the EP process decreased from 0.30-0.24 in cross-validation.

\subsection{Egg potential per RU}

Egg potential maps indicated that egg production ranges from low values (e.g. 2-5 eggs female ${ }^{-1} \mathrm{yr}^{-1}$ ) in years with unfavorable climate conditions for reproductive processes to average egg production values of 6-12 eggs female ${ }^{-1} \mathrm{yr}^{-1}$ in favorable conditions. These values differed among the 5 RUs, and among years, and some RUs benefited more from improved conditions. For example, increases in egg production relative to the lowest year were highest for the Northeastern Mojave and Upper Virgin River RUs in both moderate and high years, while increases in the more southern RUs were more modest (Fig. 4). Further, there were spatial differences in egg production potential that remained lower even in the highest years (e.g. the southernmost portion of the distribution, as well as areas near Death Valley and the Owens Valley of California) (Fig. 4-High). Annual variation in egg production potential indicates a generally declining trend over time $(p=0.02)$, with the notable exception of a single year (2004) in which reproductive potential was higher in all RUs (Fig. 4). Annual climate-driven variation in expected egg production was highly correlated among RUs, with pairwise correlation ranging from $|r|=0.91$ (Western Mojave vs. Upper Virgin River) to $|r|=0.97$ (Eastern Mojave vs. Western Mojave).

\section{DISCUSSION}

We found that precipitation and temperature at several different temporal scales influence reproductive potential for Agassiz's desert tortoise, both in the ability to produce eggs in a given year and in the total number of eggs laid. Our results underscore the combined influence of body size (Wallis et al. 1999) and local environmental conditions on reproductive output in this species. This information may be increasingly important to management for this species when accounting for future climate change, as arid areas - and in particular the desert southwest are expected to be highly influenced by climate change and to show a greater rate of temperature increase than other regions (Seager et al. 2007, Archer \& Predick 2008). Precipitation will likely be influenced as well. In the last century, some areas of the Mojave Desert have already seen a $20 \%$ reduction in precipitation (Guida et al. 2019); however, some future climate projections disagree about whether precipitation will increase or decrease for this region (Bachelet et al. 2016). Indeed, increasing aridity may already be affecting desert tortoises; over the modeled timeframe (1990-2018) our models predict a gradual but significant decline in range-wide egg production potential.

We found that increased reproductive output was associated with increased prior-year cumulative precipitation and an earlier (warmer) start to the nesting season. Interestingly, with climate change likely to result in warmer climates and potentially increased water deficits, our model suggests that earlier activity periods (resulting in increased reproductive output) could offset the negative impact of reduced precipitation. However, if climate change results in reduced forage availability (e.g. via reduced precipitation), tortoises may forgo additional reproduction attempts even if temperatures permit a longer nesting season (Henen 2002). Furthermore, earlier activity seasons could disrupt the temporal synchrony between important events that must occur (e.g. forage availability, vitellogenesis) in order for tortoises to successfully reproduce or for hatchlings to survive (Post \& Forchhammer 2008). Accurate projection of tortoise reproductive output under future non-analogue climate conditions will require further investigation into the potential for phenological mismatch or other complex interactive effects of precipitation and temperature on egg production.

The relationship we identified between cumulative prior-year precipitation and reproductive output almost certainly relates to the role of precipitation in regulating forage availability (Beatley 1974, Medica et al. 2012). The positive relationship between precipitation, and thus resource availability, and egg production observed in our study has also been observed in previous studies (Turner et al. 1986, Wallis et al. 1999, Nussear et al. 2012, Lovich et al. 2015). 
A Egg Potential Range

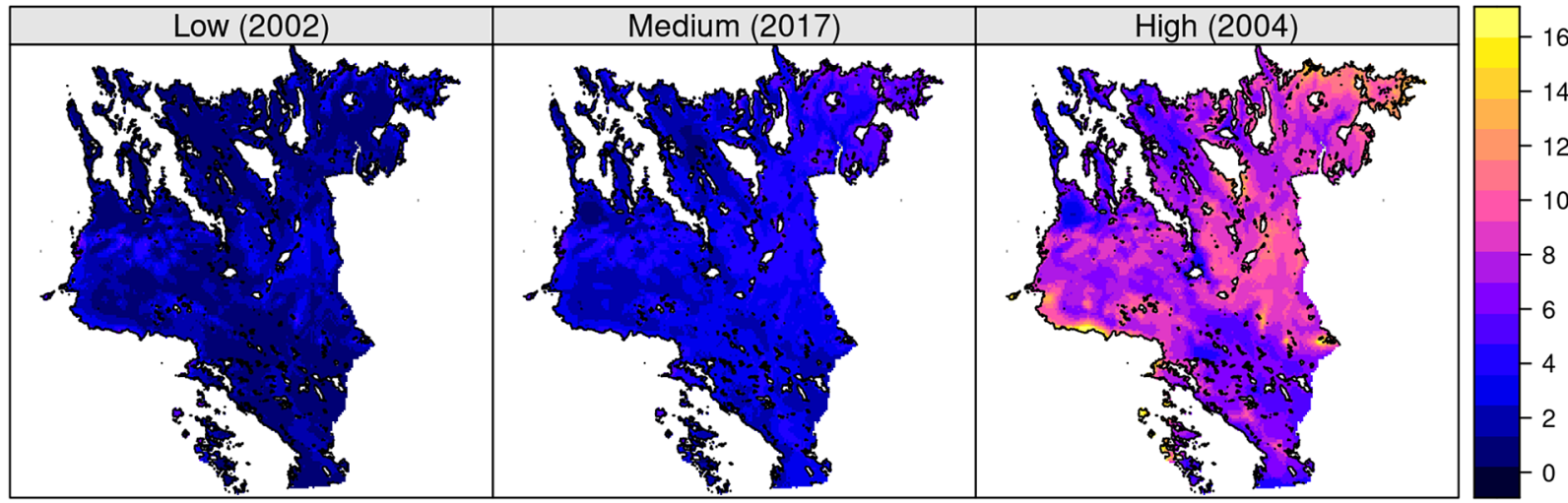

Predicted

$\mathrm{B}$
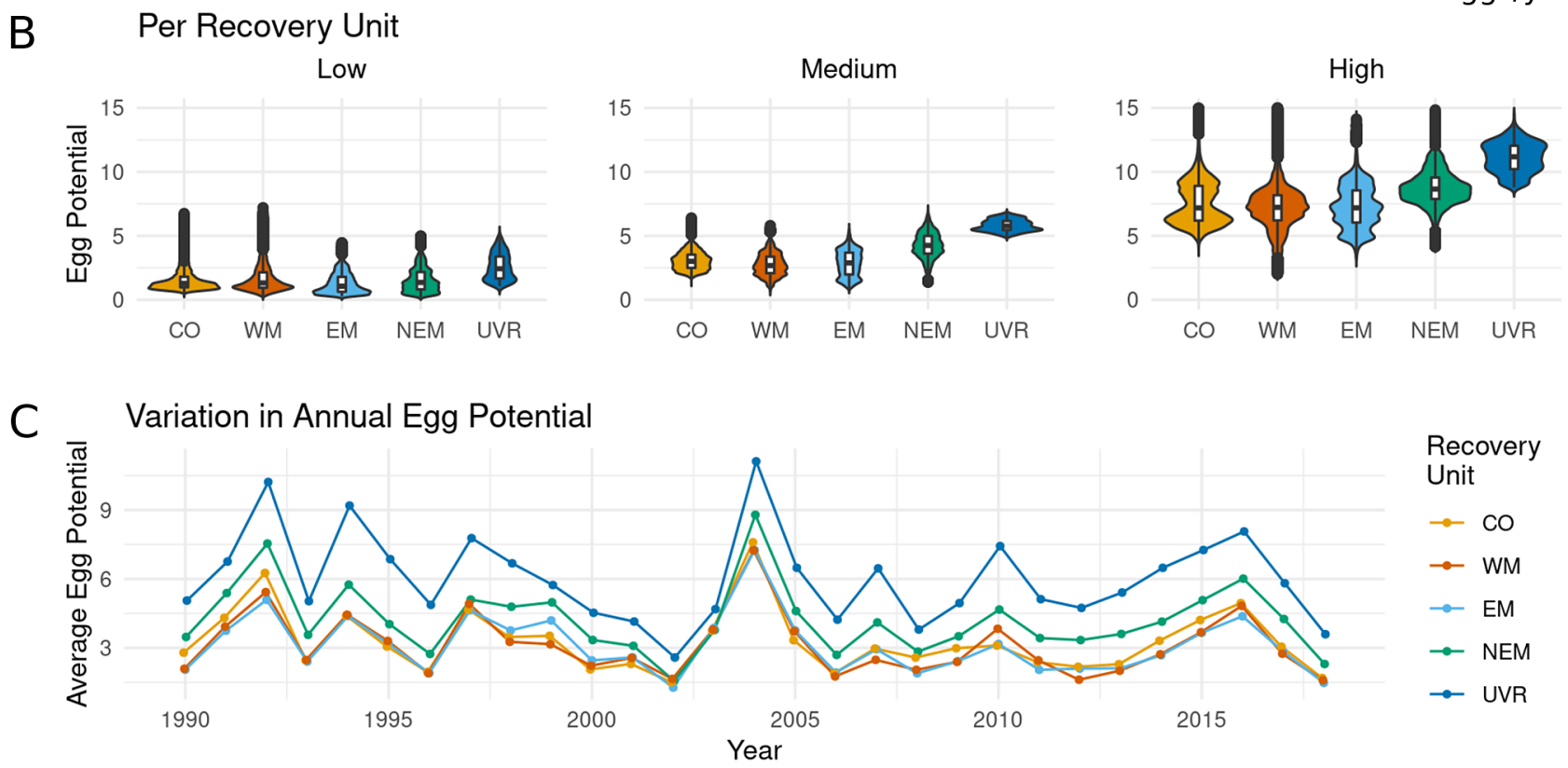

Recovery

Unit

$\rightarrow$ CO

$\rightarrow W M$

$\rightarrow$ EM

$\rightarrow$ NEM

$\rightarrow$ UVR

Fig. 4. Range-wide spatiotemporal projections of annual egg production for Agassiz's desert tortoise Gopherus agassizii. (A) Maps of expected egg potential for the years with the lowest, average ('medium'), and highest mean annual predicted egg potential (range-wide) for 1990-2018. (B) Mean annual predicted egg potential by Recovery Unit (CO: Colorado Desert; WM: Western Mojave; EM: Eastern Mojave; NEM: Northeastern Mojave; UVR: Upper Virgin River) for the same years depicted in (A), where the $25^{\text {th }}, 50^{\text {th }}$, and $75^{\text {th }}$ quartiles are given by the white bar within the violin plot representing the range of the data.

(C) Averaged annual egg potential plotted by year for the 5 Recovery Units

Although many previous studies have focused on the importance of winter precipitation in the Mojave and western Sonoran desert ecosystems (e.g. Wallis et al. 1999, Nussear et al. 2012, Lovich et al. 2015), our model results suggest that cumulative precipitation across all seasons (13 mo prior to the nesting season) may be important for reproductive success in Agassiz's desert tortoise. While not as productive as winter annuals, there is a late summer flora of Mojave annuals in years of higher summer precipitation (Beatley 1974), and this additional forage, as well as addi- tional hydration, may provide important resources that influence reproduction, and may become more important if climate change involves changes in the timing of precipitation. Our results suggest that forage availability may not only influence egg development and follicle maintenance during the spring nesting season, but it may also influence the number of follicles that reach ovulatory size in late summer/ early fall (Rostal et al. 1994). Incorporating a seasonal measure of female body condition into future analyses may provide further insight into the role of sum- 
mer vs. winter precipitation on reproductive output. For example, Averill-Murray et al. (2018) found that body condition of female Sonoran desert tortoises Gopherus morafkai, a closely related species, was positively related to multiple aspects of reproductive output, including follicle growth, clutch size, and egg width.

Our findings that the majority of tortoises (66\%) are predicted to reproduce in an average year and that tortoises exhibit substantial reproductive output even under unfavorable conditions (62\% of study animals reproduced in 1997, one of the least productive years of our study period; Fig. 4), are consistent with a bet-hedging strategy in which reproductive output is sparingly spread over many years to maximize recruitment probability in an unpredictable environment (Henen 2004, Lovich et al. 2015). Furthermore, our finding of a positive correlation between reproductive status in current and prior years may suggest that high forage availability in one year affords Agassiz's desert tortoises the ability to spread reproductive effort over more than one year. Confirming this hypothesis will require additional studies.

Our study, consistent with Wallis et al. (1999) and Lovich et al. (2012), suggests that desert tortoises can (when they are provisioned with sufficient resources for greater output) produce more eggs in years with warmer springs, possibly due to the potential for accelerated egg development and because more females are able to produce multiple clutches due to a longer nesting season. Lovich et al. (2012) observed that the development of an initial clutch was affected by spring temperatures, with clutch development delayed in cooler springs relative to warmer springs. Findings by Wallis et al. (1999) demonstrated that the earlier in the season a female desert tortoise developed an initial clutch, the greater the annual reproductive output, likely due to the potential to produce multiple clutches. In fact, previous studies have suggested that differences in total egg production among individuals are driven largely by the number of clutches laid (Turner et al. 1986, Wallis et al. 1999, but see Mueller et al. 1998). The tendency to produce multiple clutches over the course of a season is another aspect of the bet-hedging strategy used by this species (e.g. spreading the risk temporally and spatially; Ennen et al. 2017). Given that sex of the offspring in tortoises is controlled by nest temperatures (Rostal et al. 2002), the partitioning of eggs into multiple clutches may also be a factor in maintaining balanced sex ratios in populations. Further research is needed to better understand how climate change is likely to affect this complex strategy and the poten- tial for producing multiple clutches. While not included here, we hope to investigate the factors influencing the partitioning of and timing of reproductive output into multiple clutches in future analyses of these data.

The positive relationship we detected between female body size and reproductive output has been well established for many turtles (Landers et al. 1980, Gibbons 1982, Congdon \& Gibbons 1985), including the desert tortoise (Mueller et al. 1998, Wallis et al. 1999, Nussear et al. 2012). Medica et al. (2012) demonstrated that tortoise growth is dependent upon the amount of vegetation available, which in turn is highly correlated with the amount of seasonal rainfall. Thus, changes in climate that negatively impact vegetation growth could inhibit tortoise body size, which would likely cause a delay and ultimately a decrease in egg production. This suggests that changes in precipitation may cause long-term effects on reproductive output beyond the immediate impacts documented in this study. For example, climate forecasts also predict more extreme events (with respect to both temperature and precipitation; Archer \& Predick 2008), which can promote invasive plant species (e.g. Bromus spp.) with known harmful consequences for tortoise growth and nutrition (Tracy et al. 2006, Drake et al. 2016), as well as altered fire cycles that can lead to large-scale changes in habitat condition (D'Antonio \& Vitousek 1992, Van Linn et al. 2013, Horn \& St. Clair 2017).

Our study detected important range-wide spatial differences in predicted reproductive rates for Agassiz's desert tortoise. For example, our model indicates reduced reproductive capacity in southern portions of the range (Fig. 4), where habitat is also predicted to be decreasing (Barrows 2011), suggesting that those populations may experience heightened conservation challenges. In the northern portions of the range there is differential predicted reproductive potential in the western and eastern extents; the northeastern regions are predicted to have higher reproduction, while the northwestern have lower predicted rates, and less pronounced response to years with higher precipitation (Fig. 4). Our finding that predicted egg potential is higher in the northeastern portion of the range is consistent with long-term population monitoring trends, which indicate that desert tortoise density is decreasing across the range, with the exception of populations in the Northeastern RU (Allison \& McLuckie 2018). While our study found substantial spatial variation in expected reproductive output among the 5 RUs for this species, expected climate-driven temporal variation in egg production 
was highly correlated across the 5 RUs. This was not unexpected, as while the 5 RUs generally represent the genetic structure of the species, the level of genetic differentiation of tortoise populations across the range is relatively low (Hagerty \& Tracy 2010).

Ultimately, addressing range-wide management questions for Agassiz's desert tortoise and other species will require models that integrate spatiotemporal drivers of variation for all demographic processes to produce realistic expectations of species responses to environmental change (Averill-Murray et al. 2013, Zylstra et al. 2013, Campbell et al. 2015, 2018, Barrows et al. 2016). These efforts would be better if informed by additional data expressing mechanistic processes across landscapes (Kearney \& Porter 2004); however, sufficient knowledge of these processes (even in this well studied species) is generally lacking (Guisan \& Thuiller 2005) and warrants further consideration (Buckley et al. 2010). For example, a spatial PVA for the Sonoran desert tortoise included well-supported estimates of spatial variation in several key demographic parameters (Campbell et al. 2018). However, despite finding that fecundity was a key determinant of population dynamics in their system, the authors lacked sufficient data to estimate spatial variation in reproductive output (Campbell et al. 2018).

Conservation of threatened and endangered species is best done when a landscape perspective of the threats, habitat condition, and demographics of the local populations are considered in one overarching management framework. Conservation efforts for the desert tortoise are becoming increasingly coordinated (Averill-Murray et al. 2012), and the need for range-wide demographic information is of critical importance for management decisions and conservation planning efforts for this and other species facing unprecedented anthropogenic disturbance and climate change (Turner et al. 1995). The present research provides a model that can estimate a key aspect of the demographic process at a range-wide scale, and can be modified to provide insights into future climates. This information, along with similar efforts targeting other demographic processes, has the potential to aid in management of the desert tortoise and other species.

Data accessibility. All code and data for fitting this model are available at https://github.com/kevintshoemaker/Tortoise EggModel. Desert tortoise egg production data sets collected as part of several studies associated with the manuscript can also be accessed at Puffer et al. (2020). These data are published following US Geological Survey data policies.
Acknowledgements. We thank the countless field technicians that contributed toward the data analyzed here; without them, none of this research would have been possible. Dustin Haines, Mary Saethere, Kristin Murphy, Alan Green, Ron Marlow, Kathie Meyer-Wilkins, Ramona Daniels, Curt Bjurlin, Sheila Madrak, Laura Tennant, Amanda Smith, Rachel Henderson, Joshua Ennen, and Jenna Norris were especially integral to field efforts, and we thank them. We thank Mark Peadon and 3 anonymous reviewers for thoughtful comments on earlier drafts of the manuscript. This work was partially supported by the Strategic Environmental Research and Development Program (SERDP RC181103 and RC18-1207), Clark County Desert Conservation Program, the National Fish and Wildlife Foundation, the USGS, BLM, the California Energy Commission, and USFWS. We are saddened to have lost Phil Medica and Ron Marlow this year. Their contributions toward this work, and toward the conservation of desert tortoises are immeasurable. They are dearly missed. Any use of trade, product, or firm names is for descriptive purposes only and does not imply endorsement by the US Government.

\section{LITERATURE CITED}

Allison LJ, McLuckie AM (2018) Population trends in Mojave desert tortoises (Gopherus agassizii). Herpetol Conserv Biol 13:433-452

Anthonysamy WJB, Dreslik MJ, Douglas MR, Marioni NK, Phillips CA (2014) Reproductive ecology of an endangered turtle in a fragmented landscape. Copeia 2014: 437-446

Archer SR, Predick KI (2008) Climate change and ecosystems of the southwestern United States. Rangelands 30: $23-28$

*Averill-Murray RC, Darst CR, Field KJ, Allison LJ (2012) A new approach to conservation of the Mojave desert tortoise. Bioscience 62:893-899

Averill-Murray RC, Darst CR, Strout N, Wong M (2013) Conserving population linkages for the Mojave desert tortoise (Gopherus agassizii). Herpetol Conserv Biol 8:1-15

Averill-Murray RC, Christopher TE, Henen BT (2018) Reproductive ecology and life history of female Sonoran desert tortoises (Gopherus morafkai). Herpetol Monogr 32:34-50

Bachelet D, Ferschweiler K, Sheehan T, Strittholt J (2016) Climate change effects on southern California deserts. J Arid Environ 127:17-29

Bailey LD, van de Pol M (2016) climwin: an R toolbox for climate window analysis. PLOS ONE 11:e0167980

Barrows CW (2011) Sensitivity to climate change for two reptiles at the Mojave-Sonoran Desert interface. J Arid Environ 75:629-635

Barrows CW, Henen BT, Karl AE (2016) Identifying climate refugia: a framework to inform conservation strategies for Agassiz's desert tortoise in a warmer future. Chelonian Conserv Biol 15:2-11

*Beatley JC (1974) Phenological events and their environmental triggers in Mojave Desert ecosystems. Ecology 55:856-863

* Bjurlin CD, Bissonette JA (2004) Survival during early life stages of the desert tortoise (Gopherus agassizii) in the south-central Mojave Desert. J Herpetol 38:527-535

Blanchfield PJ, Ridgway MS (2005) The relative influence of breeding competition and habitat quality on female 
reproductive success in lacustrine brook trout (Salvelinus fontinalis). Can J Fish Aquat Sci 62:2694-2705

Brooks SP, Gelman A (1998) General methods for monitoring convergence of iterative simulations. J Comput Graph Stat 7:434-455

Buckley LB, Urban MC, Angilletta MJ, Crozier LG, Rissler LJ, Sears MW (2010) Can mechanism inform species' distribution models? Ecol Lett 13:1041-1054

Campbell SP, Steidl RJ, Zylstra ER (2015) Recruitment of desert tortoises (Gopherus agassizii and G. morafkai): a synthesis of reproduction and first-year survival. Herpetol Conserv Biol 10:583-591

* Campbell SP, Zylstra ER, Darst CR, Averill-Murray RC, Steidl RJ (2018) A spatially explicit hierarchical model to characterize population viability. Ecol Appl 28: 2055-2065

Carter SK, Nussear KE, Esque TC, Leinwand IIF and others (2020) Quantifying development to inform management of Mojave and Sonoran desert tortoise habitat in the American southwest. Endang Species Res 42:167-184

Clark JS (2005) Why environmental scientists are becoming Bayesians: modelling with Bayes. Ecol Lett 8:2-14

* Clarke DN, Zani PA (2012) Effects of night-time warming on temperate ectotherm reproduction: potential fitness benefits of climate change for side-blotched lizards. J Exp Biol 215:1117-1127

Congdon JD, Gibbons JW (1985) Egg components and reproductive characteristics of turtles: relationships to body size. Herpetologica 41:194-205

* D'Antonio CM, Vitousek PM (1992) Biological invasions by exotic grasses, the grass/fire cycle, and global change. Annu Rev Ecol Syst 23:63-87

Denwood MJ (2016) runjags: an R package providing interface utilities, model templates, parallel computing methods and additional distributions for MCMC models in JAGS. J Stat Softw 71:1-25

* Drake KK, Bowen L, Nussear KE, Esque TC and others (2016) Negative impacts of invasive plants on conservation of sensitive desert wildlife. Ecosphere 7:e01531

* Edwards T, Berry KH, Inman RD, Esque TC, Nussear KE, Jones CA, Culver M (2015) Testing taxon tenacity of tortoises: evidence for a geographical selection gradient at a secondary contact zone. Ecol Evol 5:2095-2114

Ennen JR, Lovich JE, Averill-Murray RC, Yackulic CB and others (2017) The evolution of different maternal investment strategies in two closely related desert vertebrates. Ecol Evol 7:3177-3189

Ernst CH, Lovich JE (2009) Turtles of the United States and Canada, $2^{\text {nd }}$ edn. The Johns Hopkins University Press, Baltimore, MD

* Gelman A (2013) Two simple examples for understanding posterior $p$-values whose distributions are far from uniform. Electron J Stat 7:2595-2602

Gelman A, Carlin JB, Stern HS, Dunson DB, Vehtari A, Rubin DB (2013) Bayesian data analysis. CRC Press, Philadelphia, PA

Gibbons JW (1982) Reproductive patterns in freshwater turtles. Herpetologica 38:222-227

Guida RJ, Abella SR, Roberts CL, Norman CM, Smith WJ (2019) Assessing historical and future habitat models for four conservation-priority Mojave Desert species. J Biogeogr 46:2081-2097

Guisan A, Thuiller W (2005) Predicting species distribution: offering more than simple habitat models. Ecol Lett 8: 993-1009
Hagerty BE, Tracy CR (2010) Defining population structure for the Mojave desert tortoise. Conserv Genet 11: 1795-1807

Heidelberger P, Welch PD (1983) Simulation run length control in the presence of an initial transient. Oper Res 31: 1109-1144

Henen BT (2002) Energy and water balance, diet, and reproduction of female desert tortoises (Gopherus agassizii). Chelonian Conserv Biol 4:319-329

*Henen BT (2004) Capital and income breeding in two species of desert tortoise. Trans R Soc S Afr 59:65-71

* Horn KJ, St. Clair SB (2017) Wildfire and exotic grass invasion alter plant productivity in response to climate variability in the Mojave Desert. Landsc Ecol 32:635-646

Kearney M, Porter WP (2004) Mapping the fundamental niche: physiology, climate, and the distribution of a nocturnal lizard. Ecology 85:3119-3131

Kéry M (2010) Introduction to WinBUGS for ecologists: a Bayesian approach to regression, ANOVA, mixed models and related analyses, $1^{\text {st }}$ edn. Elsevier, Amsterdam

Lamberski N (2013) Body condition scores of desert tortoises. US Fish and Wildlife Service report. https://www.fws. gov/nevada/desert_tortoise/documents/reports/2013/ assess/Desert-Tortoise-BCS-2013-lamberski-po.pdf (accessed September 2020)

Landers JL, Garner JA, McRae WA (1980) Reproduction of gopher tortoises (Gopherus polyphemus) in southwestern Georgia. Herpetologica 36:353-361

* Longshore KM, Jaeger JR, Sappington JM (2003) Desert tortoise (Gopherus agassizii) survival at two eastern Mojave Desert sites: Death by short-term drought? J Herpetol 37 : 169-177

Lovich JE, Medica P, Avery H, Meyer K, Bowser G, Brown A (1999) Studies of reproductive output of the desert tortoise at Joshua Tree National Park, the Mojave National Preserve, and comparative sites. Park Sci 19:22-24

Lovich JE, Agha M, Meulblok M, Meyer K and others (2012) Climatic variation affects clutch phenology in Agassiz's desert tortoise Gopherus agassizii. Endang Species Res 19:63-74

K Lovich JE, Ennen JR, Yackulic CB, Meyer-Wilkins K and others (2015) Not putting all their eggs in one basket: bet-hedging despite extraordinary annual reproductive output of desert tortoises. Biol J Linn Soc 115:399-410

*Lovich JE, Ennen JR, Agha M, Gibbons JW (2018a) Where have all the turtles gone, and why does it matter? Bioscience 68:771-781

Lovich JE, Puffer SR, Agha M, Ennen JR and others (2018b) Reproductive output and clutch phenology of female Agassiz's desert tortoises (Gopherus agassizii) in the Sonoran Desert region of Joshua Tree National Park. Curr Herpetol 37:40-57

Lovich JE, Puffer SR, Cummings KL (2019) Establishing an Agassiz's desert tortoise monitoring program within the Coachella Valley multiple species habitat conservation plan area. In: 2019 Annual Report: Coachella Valley multiple species conservation plan/natural community conservation plan. Coachella Valley Conservation Commission, Palm Desert, CA

Medica PA, Nussear KE, Esque TC, Saethre MB (2012) Long-term growth of desert tortoises (Gopherus agassizii) in a Southern Nevada population. J Herpetol 46: 213-220

*Mueller JM, Sharp KR, Zander KK, Rakestraw DL, Rautenstrauch KR, Lederle PE (1998) Size-specific fecundity of 
the desert tortoise (Gopherus agassizii). J Herpetol 32: 313-319

Nagy KA, Medica PA (1986) Physiological ecology of desert tortoises in Southern Nevada. Herpetologica 42:73-92

Noy-Meir I (1973) Desert ecosystems: environment and producers. Annu Rev Ecol Syst 4:25-51

Nussear KE, Esque TC (2019) Desert biogeography: Mojave. In: Goldstein MI, DellaSala DA (eds) Encyclopedia of the world's biomes. Elsevier, Amsterdam, p 99-109

Nussear KE, Esque TC, Haines DF, Richard Tracy C (2007) Desert tortoise hibernation: temperatures, timing, and environment. Copeia 2007:378-386

Nussear KE, Tracy CR, Medica PA, Wilson DS, Marlow RW, Corn PS (2012) Translocation as a conservation tool for Agassiz's desert tortoises: survivorship, reproduction, and movements. J Wildl Manag 76:1341-1353

* Plummer M (2017) JAGS version 4.3.0 user manual. https:// sourceforge.net/projects/mcmc-jags/files/

* Post E, Forchhammer MC (2008) Climate change reduces reproductive success of an Arctic herbivore through trophic mismatch. Philos Trans R Soc B 363:2369-2375

Powell BF, Steidl RJ (2000) Nesting habitat and reproductive success of southwestern riparian birds. Condor 102: 823-831

PRISM Climate Group (2019) PRISM Climate Group, Oregon State University. http://prism.oregonstate.edu (accessed April 2019)

Puffer SR, Lovich JE, Cummings KL (2020) Agassiz's desert tortoise and egg data from the Sonoran Desert of California (1997-2000, 2015-2018). US Geological Survey data release. https://doi.org/10.5066/P97XT7HF

R Core Team (2019) R: a language and environment for statistical computing. R Foundation for Statistical Computing, Vienna

Reed JM, Fefferman N, Averill-Murray RC (2009) Vital rate sensitivity analysis as a tool for assessing management actions for the desert tortoise. Biol Conserv 142: 2710-2717

Rostal DC, Lance VA, Grumbles JS, Alberts AC (1994) Seasonal reproductive cycle of the desert tortoise (Gopherus agassizii) in the eastern Mojave Desert. Herpetol Monogr 8:72-82

Rostal DC, Wibbels T, Grumbles JS, Lance VA, Spotila JR (2002) Chronology of sex determination in the desert tortoise (Gopherus agassizii). Chelonian Conserv Biol 4: 313-318

* Seager R, Ting M, Held I, Kushnir Y and others (2007) Model projections of an imminent transition to a more arid climate in southwestern North America. Science 316:1181-1184

Smith GR, Ballinger RE, Rose BR (1995) Reproduction in Sceloporus virgatus from the Chiricahua Mountains of southeastern Arizona with emphasis on annual variation. Herpetologica 51:342-349

* Stearns SC (1976) Life-history tactics: a review of the ideas. Q Rev Biol 51:3-47

Thornton PE, Thornton MM, Mayer BW, Wei Y, Devarakonda R, Vose RS, Cook RB (2018) Daymet: daily surface weather data on a 1-km grid for North America. Oak Ridge National Laboratory DAAC, Oak Ridge, TN

Editorial responsibility: Mark Hamann,

Townsville, Queensland, Australia

Reviewed by: 3 anonymous referees
Tracy CR, Nussear KE, Esque TC, Dean-Bradley K and others (2006) The importance of physiological ecology in conservation biology. Integr Comp Biol 46:1191-1205

* Turner FB, Medica PA, Lyons CL (1984) Reproduction and survival of the desert tortoise (Scaptochelys agassizii) in Ivanpah Valley, California. Copeia 1984:811-820

Turner FB, Hayden P, Burge BL, Roberson JB (1986) Egg production by the desert tortoise (Gopherus agassizii) in California. Herpetologica 42:93-104

* Turner MG, Arthaud GJ, Engstrom RT, Hejl SJ, Liu J, Loeb S, McKelvey K (1995) Usefulness of spatially explicit population models in land management. Ecol Appl 5: $12-16$

USFWS (US Fish and Wildlife Service) (1990) Endangered and threatened wildlife and plants; determination of threatened status for the Mojave population of the desert tortoise. Fed Regist 55:12178-12191

USFWS (2011) Revised recovery plan for the Mojave population of the desert tortoise (Gopherus agassizii). US Fish and Wildlife Service, Pacific Southwest Region, Sacramento, CA

* van de Pol M, Vindenes Y, Sæther BE, Engen S, Ens BJ, Oosterbeek K, Tinbergen JM (2010) Effects of climate change and variability on population dynamics in a longlived shorebird. Ecology 91:1192-1204

van de Pol M, Bailey LD, McLean N, Rijsdijk L, Lawson CR, Brouwer L (2016) Identifying the best climatic predictors in ecology and evolution. Methods Ecol Evol 7:1246-1257

*Van Linn PF, Nussear KE, Esque TC, DeFalco LA, Inman RD, Abella SR (2013) Estimating wildfire risk on a Mojave Desert landscape using remote sensing and field sampling. Int J Wildland Fire 22:770-779

Vleck CM, Vleck D (2002) Physiological condition and reproductive consequences in Adelie penguins. Integr Comp Biol 42:76-83

*Wallis IR, Henen BT, Nagy KA (1999) Egg size and annual egg production by female desert tortoises (Gopherus agassizii): the importance of food abundance, body size, and date of egg shelling. J Herpetol 33:394-408

Kanette L, Clinchy M, Smith JNM (2006) Combined food and predator effects on songbird nest survival and annual reproductive success: results from a bi-factorial experiment. Oecologia 147:632-640

Zeh JA, Bonilla MM, Su EJ, Padua MV and others (2012) Degrees of disruption: projected temperature increase has catastrophic consequences for reproduction in a tropical ectotherm. Glob Change Biol 18:1833-1842

* Zimmerman LC, O'Connor MP, Bulova SJ, Spotila JR, Kemp SJ, Salice CJ (1994) Thermal ecology of desert tortoises in the Eastern Mojave Desert: seasonal patterns of operative and body temperatures, and microhabitat utilization. Herpetol Monogr 8:45-59

Zuur AF, Ieno EN, Walker NJ, Saveliev AA, Smith GM (2009) Zero-truncated and zero-inflated models for count data. In: Mixed effects models and extensions in ecology with R. Springer, New York, NY, p 261-293

Zylstra ER, Steidl RJ, Jones CA, Averill-Murray RC (2013) Spatial and temporal variation in survival of a rare reptile: a 22-year study of Sonoran desert tortoises. Oecologia 173:107-116

Submitted: August 19, 2020

Accepted: December 11, 2020

Proofs received from author(s): March 3, 2021 